Claudia Dumit

\title{
O transporte ferroviário de carga no Brasil: Estudo de caso do transporte de combustíveis na Região Sul
}

Dissertação apresentada como requisito parcial para obtenção do título de Mestre (opção profissional) pelo Programa de Pós-Graduação em Engenharia Industrial da PUC-Rio.

Orientador: Nélio Domingues Pizzolato

Rio de Janeiro, outubro de 2005. 
Claudia Dumit

\title{
O transporte ferroviário de carga no Brasil: Estudo de caso do transporte de combustíveis na Região Sul
}

\begin{abstract}
Dissertação apresentada como requisito parcial para obtenção do título de Mestre (opção profissional) pelo Programa de Pós-Graduação em Engenharia Industrial da PUC-Rio, Aprovada pela Comissão Examinadora abaixo assinada.
\end{abstract}

Prof. Nélio Domingues Pizzolato Orientador

Departamento de Engenharia Industrial - PUC-Rio

Prof. José Eugênio Leal Departamento de Engenharia Industrial - PUC-Rio

Prof. Luiz Felipe Scavarda

Departamento de Engenharia Industrial - PUC-Rio

Prof. José Eugênio Leal Coordenador Setorial do Centro Técnico-Científico - PUC-Rio

Rio de Janeiro, 07 de outubro de 2005. 
Todos os direitos reservados. É proibida a reprodução total ou parcial do trabalho sem autorização da universidade, do autor e do orientador.

\section{Claudia Dumit}

Graduou-se em Administração de Empresas na Universidade Estácio de Sá. Cursou o MBA em Logística Empresarial na FGV em 2001. Concluiu a Pós-Graduação em Finanças na Universidade Candido Mendes-RJ em 2003. Possui experiência profissional de 10 anos em Logística e atua na área de Logística de Petróleo de uma distribuidora de combustíveis.

Ficha Catalográfica

Dumit, Claudia

O transporte ferroviário de carga no Brasil: Estudo de caso do transporte de combustíveis na Região Sul / Claudia Dumit ; orientador: Nélio Domingues Pizzolato. - Rio de Janeiro : PUC, Departamento de Engenharia Industrial, 2005.

85 f. : il. ; $30 \mathrm{~cm}$

Dissertação (mestrado) - Pontifícia Universidade Católica do Rio de Janeiro, Departamento de Engenharia Industrial.

Inclui referências bibliográficas.

1. Engenharia industrial - Teses. 2. Transporte Ferroviário. 3. Logística do petróleo. 4. Estoque de Segurança. I. Pizzolato, Nélio Domingues. II. Pontifícia Universidade Católica do Rio de Janeiro. Departamento de Engenharia Industrial. III. Título. 


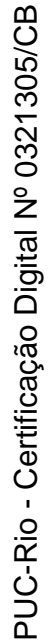

Para minha querida Mãe, minha eterna gratidão.

Para meu querido Esposo, meu eterno amor. 


\section{Agradecimentos}

Ao meu orientador Nélio Pizzolato pelo apoio e dedicação na realização desta dissertação.

A PUC - RJ pela oportunidade de cursar o Mestrado.

Ao Vice-Reitor Acadêmico, Augusto Sampaio, por toda a ajuda nos momentos difíceis ao longo desses dois anos.

A minha Família por estar sempre zelando por meu bem-estar e pela compreensão de minhas ausências em detrimento à conclusão desse trabalho.

Aos meus Colegas do Mestrado, pelos bons momentos de descontração.

A todos que de alguma forma participaram direta ou indiretamente para a conclusão do estudo. 


\section{Resumo}

Dumit, Claudia. O transporte ferroviário de carga no Brasil: Estudo de caso do transporte de combustíveis na Região Sul. Rio de Janeiro, 2005. 85p. Dissertação de Mestrado - Departamento de Engenharia Industrial, Pontifícia Universidade Católica do Rio de Janeiro.

Esta dissertação aborda a evolução da malha ferroviária brasileira e o impacto deste modal de transporte nos estoques de Diesel e Gasolina das Bases de Distribuição localizadas no Sul do Brasil, pertencentes a uma importante distribuidora de derivados de petróleo. A relevância do estudo realizado deve-se à aprovação da Lei 9.478 - Lei do Petróleo - que quebrou o monopólio da Petrobras neste setor, transferindo para as distribuidoras o gerenciamento espacial e volumétrico de seus estoques. Por outro lado, o estudo contribui para o conhecimento da incipiente malha ferroviária brasileira, a partir da privatização ocorrida em 1996, e tornada importante diante da crescente necessidade de se agregar valor, eficiência e segurança ao transporte de combustíveis. O objetivo deste estudo é abordar a evolução da malha ferroviária brasileira e o impacto deste modal de transporte nos estoques de segurança de Diesel e Gasolina de uma grande Distribuidora de derivados de petróleo e o relacionamento dos custos de transporte atrelados aos riscos e impontualidade ainda prevalecentes no sistema ferroviário.

\section{Palavras-chave:}

Transporte Ferroviário, Logística do Petróleo, Estoque de Segurança. 


\section{Abstract}

Dumit, Claudia. Railroad cargo transportation in Brazil: Case study of fuel transportation in South Region... Rio de Janeiro, 2005. 85f. MSc Dissertation - Departamento de Engenharia Industrial, Pontifícia Universidade Católica do Rio de Janeiro.

This thesis approaches the evolution of the Brazilian railroad mesh and the impact of this modal of transportation to an important company in the supplies of Diesel and Gasoline to the Bases of Distribution located in the South of Brazil. The relevance of this study is justified due to the approval of Law 9.478 - Law of the Oil - that broke the monopoly of Petrobras in this sector, transferring to oil companies the spatial and volumetric management of their oil inventories. On the other hand, the study contributes for the knowledge of the incipient Brazilian railroad mesh, privatized in 1996, and becoming increasingly important giving the necessity of adding value, efficiency and security to the fuel transportation. The objective of the present study is the evolution of railroad mesh and the impact of this transportation modal on Gasoline and Diesel safety stocks handled by an important oil company and its relationship to the costs of transportation related to the risks and unpunctuality still prevailing in the railroad system.

\section{Keywords:}

Railroad Transportation, Oil Logistics, Safety Stock. 


\section{SUMÁRIO}

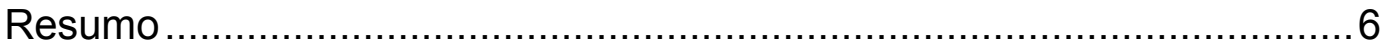

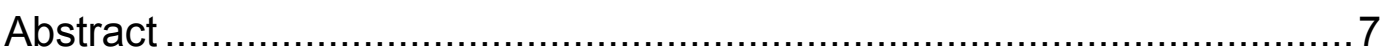

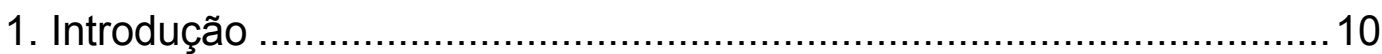

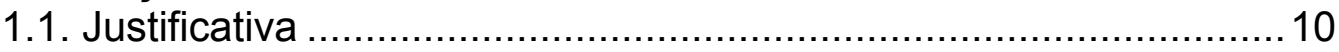

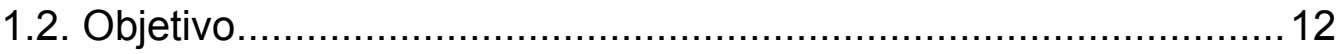

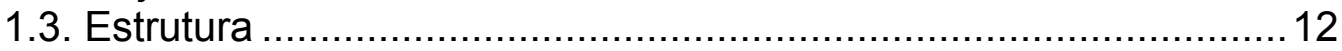

1.4. Metodologia ........................................................................ 14

2. A Indústria do Petróleo no Brasil ................................................. 15

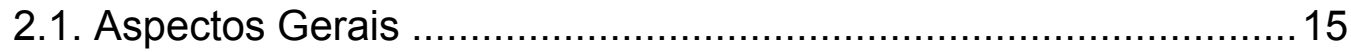

2.2. Principais Atividades.......................................................... 18

2.2.1. Exploração ...................................................................... 18

2.2.2. Explotação .................................................................. 18

2.2.3. Refino ....................................................................... 18

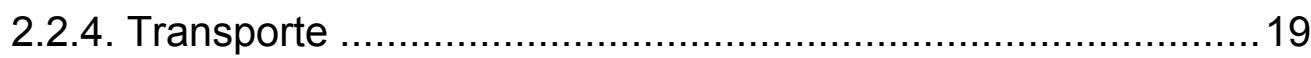

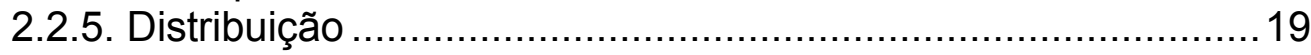

2.3. O Segmento de Downstream .................................................. 20

3. A Logística como Fator de Competitividade ................................... 24

4. Logística da Indústria do Petróleo ................................................ 27

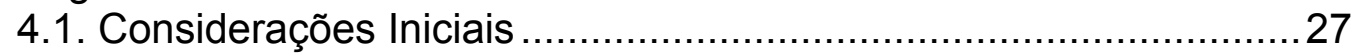

4.2. Distribuição de Derivados de Petróleo .......................................29

4.3. Bases de Distribuição ............................................................ 30

4.3.1. Bases de Distribuição - Primárias ou Principais ..................... 31

4.3.2. Bases Secundárias ou de Interior ..................................... 31

5. Transporte de Cargas no Brasil....................................................... 34

5.1. Evolução Histórica do Transporte de Cargas ............................ 34

5.2. Transportes e Desenvolvimento Econômico............................... 35

5.3. Evolução da Malha Ferroviária Brasileira .................................. 36

5.3.1. O Surto das Ferrovias no Século XIX ................................. 36

5.4. O Processo de Privatização dos Transportes no Brasil ................. 40

5.4.1. Perfil da Malha Ferroviária no Pós-Privatização .....................42 42

6.O Modal Ferroviário na Matriz de Transportes e o Transporte Ferroviário

de Combustíveis...................................................................................4 47

6.1. Medidas Preventivas e Corretivas para o Transporte Ferroviário de

Combustíveis ....................................................................................4 49

6.2. Ações Aplicadas pelas Ferrovias ............................................ 49

6.2.1. Ações Preventivas......................................................50

6.2.2. Ações Corretivas ........................................................ 50

6.2.2.1. Legislação Básica ..................................................... 50

6.2.2.2. Plano de Atendimento Emergencial............................ 51

6.3. Entraves na Infra-Estrutura do Transporte Ferroviário...................51

6.3.1. Proposta de Solução do Problema .......................................52

6.3.1.1. Invasões na Faixa de Domínio das Ferrovias ..................52

6.3.1.2. Passagens em Nível Críticas ........................................ 52

6.3.1.3. Gargalos Operacionais e Físicos ................................53

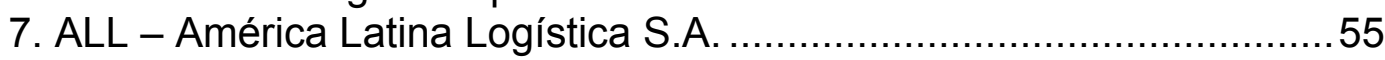

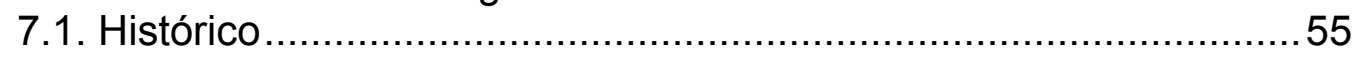

7.2. Investimentos da ALL - América Latina Logística S.A. ..................59

8. Estudo de Caso.................................................................... 64 


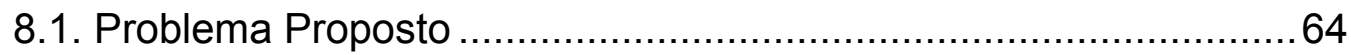

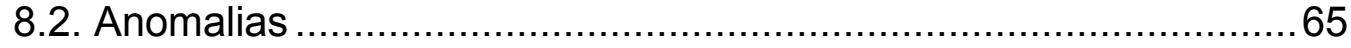

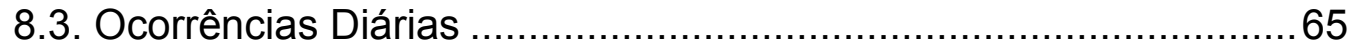

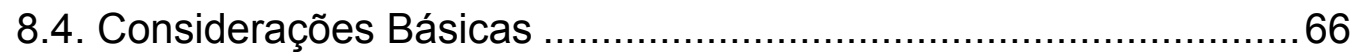

8.5. Modelos Utilizados para a Busca da Solução.................................66

8.6. Situação Atual de Suprimento e Cálculo do Estoque de Segurança

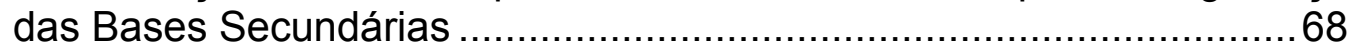

8.7. Incremento de Estoque ........................................................

8.8. Gastos Com Transferências Rodoviárias ...................................73

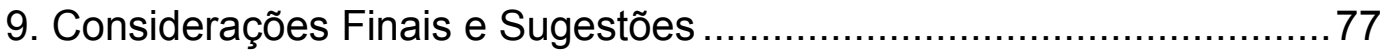

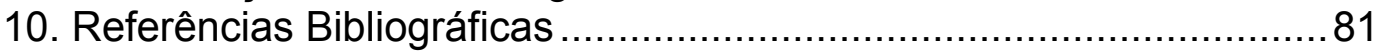

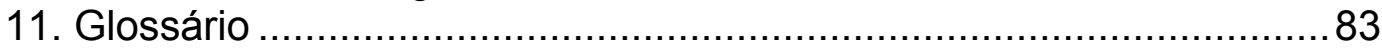

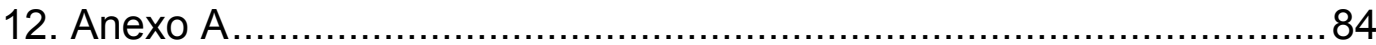

